\title{
The experiences, perceptions and challenges of mothers managing asthma in their children: a qualitative study
}

\author{
Hatice Pars ${ }^{1 \oplus}$, Özge Soyer ${ }^{2 \oplus}$, Bülent Enis Şekerel ${ }^{2 \oplus}$ \\ ${ }^{1}$ Department of Pediatric Nursing, Hacettepe University Faculty of Nursing, Ankara; ${ }^{2}$ Department of Pediatric Allergy, Hacettepe \\ University Faculty of Medicine, Ankara, Turkey.
}

\begin{abstract}
Background. Despite the fact that childhood asthma poses an important burden, especially on the families, little is known about the emotional experiences of mothers. This article describes the predominant emotional challenges and experiences reported by mothers of children with asthma.

Methods. Individual, semi-structured, in-depth interviews with a qualitative study method was used in collection of the data. Face-to-face interviews with mothers of children with asthma were conducted using sociodemographic data form and semi-structured interview forms developed by the investigators. The transcribed interview texts were analyzed according to a qualitative content analysis.
\end{abstract}

Results. A total of 20 mothers were interviewed. We found that the experience of mothers of the children with asthma was a strenuous journey of overriding an emotional rollercoaster, that is, from being thrown into a chaotic situation to later processing the difficult situation affected by the asthma. First moment at diagnosis, relaxation against uncertainties, anxiety, fear, truly acceptance, sadness were the predominant emotions. Mothers described experiences and challenges of frequent admission to emergency, administration of medication and treatments, school problems, limitations in physical activity and spouse relationship problems. Experiences of problems contributed to hopelessness, abandoned, angry and burnout. Mothers had concerns about the chronic nature of the disease, side effects of medications, complications that might develop, factors influencing the disease, and future plans.

Conclusions. Mothers of children with asthma described complex emotional journeys. This has implications for healthcare providers who need to be aware of the complexity of these emotional journeys to support parents more effectively, thereby helping improve patient outcomes. Parents should be trained for symptoms and disease management with a written action plan. It is imperative to realize multi-disciplinary team collaboration and to regularly review training and information. Future research should concentrate on promoting awareness, education, advocacy, and support for parents of asthmatic children.

Key words: asthma, caregivers, child, mothers, qualitative.

Asthma may decrease quality of life in children as it affects their physical, mental, social, and emotional development. ${ }^{1,2}$ If asthma is uncontrolled, children may experience frequent emergency department admissions and hospitalizations along with many attrition from school and limitations in their daily activities such as playing, extracurricular activities, and

$凶$ Hatice Pars

hatice.saglam.hs@gmail.com

Received 04th June 2020, revised 17 July 2020,

20th July 2020, accepted 21st July 2020. doing sports. Parents have a critical role in the management of the disease, however, this situation may have a serious psychological effect on parents which, can lead to feelings of inadequacy, helplessness and depression.,4 Families' adaptation tothediseaseand difficulties in asthma management may influence asthma control. Previous studies in other countries have reported that parents may have insufficient knowledge on triggers, insufficient information for the care and difficulties on the recognition of asthma symptoms. ${ }^{5-7}$ Parents' attitudes towards diseases are, to a certain extent, a 
reflection of the cultural characteristics and the health infrastructure of that society. Only few studies have been performed in Turkey for the perception of asthma on children ${ }^{8}$, pharmacists $^{9}$, and physicians ${ }^{10}$ but not on parents, hence this needs to be documented to improve asthma management. In our country, no study investigating the families' difficulties in managing asthma could be found.

As healthcare professionals, in order for us to help the child with asthma and the caregiver, it is very important to examine the real experiences of mothers during the caregiving process. Knowing the characteristics of caregiving mothers, having comprehensive knowledge about their experience, knowledge, and perceptions, determining the care to be given by healthcare institutions, improving this care, determining the sources for the service to be offered, determining the groups that are under risk of experiencing difficulty, establishing the groups according to these characteristics, and determining the need for education and knowledge are very important. For this reason, the qualitative studies on the difficulties, perceptions, and personal experiences of parents of children with asthma during the disease process are needed. The present study aims to document the experience, perceptions and challenges of mothers who have a child with asthma, therefore provide insights for better precautions to be taken in this regard.

\section{Material and Methods}

\section{Study Design and Study Population}

The present descriptive-qualitative study was carried out using the semi-structured interview method. A semi-structured survey form was used in in-depth interviews in order to determine the concerns of parents related to treatment and care.

The study population consisted of mothers of children who were followed up in the allergy outpatient department of Hacettepe University
Ihsan Dogramac1 Children's Hospital. At the beginning of the study, no specific number of study subjects was specified and it was planned to stop when adequate data was achieved. In other words, it was aimed to achieve data satisfaction in in-depth interviews. ${ }^{11,12}$ By using purposeful sampling method, in-depth interviews were conducted with mothers.

The volunteer mothers, who had children diagnosed with at least 1 year and aged $<5$ years with a Turkish version of "Test for Respiratory and Asthma Control in Kids (TRACK)"13,14 questionnaire total score of 80 and below (lack of good control over disease), no chronic disease other than asthma, and no communication or speaking disability, were involved. Since the group that could successfully manage the asthma process was fully controlled, the parents in this group have less experience on the difficulties in asthma management. Since the main target here is to examine thoroughly the families having difficulties during asthma management, the families that are under full-control according to TRACK test were not involved in the present study. The families in this group generally visit the departments for routine checks and have medication prescriptions. The present study was completed with 20 mothers having a child with asthma.

\section{Data Collection Forms}

Family and Child Information Form: This form included questions about the sociodemographic characteristics of children and their parents, information about the disease and treatment, and total score in TRACK.

\section{The interview schedule}

Using the semi-structured interview guideline prepared by the researchers, the open-ended questions about what they know about asthma, how it affects their lives, which difficulties they have had, what they have done during such difficulties, what they have experienced in this process, and which coping mechanisms they have used were asked. By asking questions such 
as "Could you please provide more information about this subject" or "Could you please give more details", it was aimed to comprehensively examine the topic.

Test for Respiratory and Asthma Control in Kids: TRACK is a test that has proven reliability and validity. ${ }^{13}$ The Turkish version of TRACK questionnaire, validity and reliability of which were shown before ${ }^{14}$, was used. The TRACK questionnaire was developed for children aged $<5$ years in accordance with the guidelines of National Asthma Education and Prevention Program of the USA. It includes five items about the frequency of symptoms in the last four weeks, awakening at night and activity constraints due to symptoms, frequency of use of bronchodilator in the last three months, and use of oral corticosteroid within last year. Each of the items is rated between 0 and 20 points. Scores higher than 80 points indicate good control of the disease, scores between 60 and 80 points indicate partial control, and those lower than 60 points indicate an uncontrolled disease. Those children with a TRACK score $\leq 80$ were involved in the present study

\section{Data Collection Procedure}

In the present study, the patients coming for examination in the department and meeting the inclusion criteria were examined by assistant researchers and the patients, who were "not controlled" according to TRACK test and who voluntarily participated, were referred to the primary investigator (PI). The PI met the patients in the outpatient environment and informed them about the objective and implementation steps of the research before every interview. The PI informed them that the patients would be asked questions by making use of a guideline and the patients would have an opportunity to talk as long as they want. In order to establish a warm connection with patients at the beginning of interviews, the descriptive patient information forms were filled first and, by making use of voice recording the families concerns, perceptions, and difficulties during the management of asthma were comprehensively analyzed.

The interview schedule was not strictly followed, instead it was adapted to mother' narratives and included in the process of reflecting and probing of what was important, for example, by responding: 'you said that ... tell more about that ..., what were your feelings.' The interviews lasted between 30 and 45 minutes and were conducted in a quiet room. The interviews were recorded using a voice recorder and were performed by the PI, who has been certified for this research method. The face-to-face interviews were continued until reaching the saturation and the data repeated themselves. Although the data saturation was achieved in some of questions, the data saturation was achieved in the 20th interview because different answers were given to the other questions and the process was stopped at the 20th interview. The data were collected between 1st November and 31st December 2019.

\section{Data Analysis}

The data were analyzed using SPSS 23 statistical software for descriptive statistics (percentage, mean values, standard deviation, and minimummaximum values). The interviews were recorded digitally and transcribed verbatim. The first stage involved becoming familiar with the transcript and noting any essential aspects, observations, and preliminary interpretations. Then emerging themes were noted and transformed into more specific themes, which were clustered by connecting them, followed by capturing the main categories of meaning conveyed by the participants. At the end of the process, a summary of the higher- order themes were conducted. The first and the second author read the transcripts and developed the thematic framework independent of each other. The two authors also decided together which themes best described the parents' lived experiences. Finally, the third author read the themes and analyses to ensure that the meaning of the participants' narratives was significant. 


\section{Ethics and Informed Consent}

The Non-Interventional Ethics Committee of Hacettepe University (08th January 2019, GO 19/36) approved the study. Written informed consents of the patients' legal guardians were obtained during diagnosis for use of patient data in scientific publications. The participant was not harmed in any physical or emotional manner. All possible or adequate information on the goal of the investigation; the procedures that were followed during the investigation; the possible advantages, disadvantages, and dangers to which the participant might have been exposed to; as well as the credibility of the researchers was disclosed to the participant. The participant was given information about what the study entails and what would be expected from the participant. This allowed her to make a voluntary decision to take part in the study. They were able to withdraw from the study at any time. The PI explained to the participant that emotions, such as uneasiness, might be experienced as she recalled previous unpleasant experiences. The participant's real names were not used. The participant had no concerns or reservations about the content of the interview. The transcripts therefore remained unchanged and did not influence the analysis and interpretation of the data.

\section{Trustworthiness}

To ensure trustworthiness, peer debriefing was used, where the research process and findings were reviewed and discussed with unbiased colleagues. Due to the fact that researchers possess specific knowledge on the research subject, it influenced the choice of design and interpretation and conclusion of results to some degree. They knew what they were looking for and were able to be more focused during the data collection process. The literature review allowed them to apply logical reasoning and interpretation of the data collected. Direct quotations from the interviews that were conducted were included.

\section{Results}

A total of 20 children ( $60 \%$ boys) with a mean age of $3.88 \pm 0.80$ years whose mothers were 36 (25-40) years old were included in the study. From these children $70 \%$ were on regular inhaled corticosteroid treatment and there were no reports of hospitalization, but there were on average 3 (1-7) emergency admittances during the past year. The mean (SD) TRACK score was $44 \pm 12.27$. Table I presents the study sample characteristics.

The results are presented in five themes: feelings at diagnosis; feelings during the treatment; challenges, concerns und suggestions comprehended by the overall theme an emotional rollercoaster (Fig. 1). In the following quotations, the mother is denoted as $\mathrm{M}$. The number denotes quotations cited from the 20 different interviews.

\section{Emotional rollercoaster}

Mothers reported that they were suddenly thrown into a chaotic situation, which often started with a sudden and unclear attacks, followed with enduring time of uncertainty of the process and, moreover, continued with learning successively to understand the circumstances they were set for and finally bringing the experience of having a child with asthma, putting into words how it all affected them.

\section{The feelings of mothers at diagnosis}

From the beginning, the parents found it very difficult to see their children constantly getting sick due to an unclear cause. The mothers experienced a relief when they heard the diagnosis because no exact diagnosis could be made in this process but the asthma diagnosis after the recurrent use of antibiotics removed the uncertainties, the anxiety and fear about the adverse effects of medications and potential permanency of disease, sadness because of the negative experience and speculations about the diagnosis, and true acceptance because sibling 
Table I. Characteristics of study participants $(n=20)$.

\begin{tabular}{lcc}
\hline Characteristics & Mean (SD) & Min-max \\
\hline Mother's Age (years) & $36 \pm 1.80$ & $25-40$ \\
Child's Age (years) & $3.88 \pm 0.80$ & $2-5$ \\
Treatment duration (years) & $2 \pm 0.40$ & $1-3$ \\
Emergency admittances within last year & $3 \pm 1.0$ & $1-7$ \\
TRACK score & $44 \pm 12.27$ & $5-60$ \\
Highest education level & $\mathrm{n}(\%)$ & \\
$\quad$ High school & $17(85)$ & \\
$\quad$ University & $3(15)$ & \\
Current employment status & & \\
$\quad$ Employed full-time & $5(25)$ & \\
$\quad$ At home full-time caregiver & $15(75)$ & \\
Family annual income & & \\
Less than 3000 TL & $1(5)$ & \\
$3001-5000$ TL & $14(70)$ & \\
More than 5000 TL & $5(25)$ & \\
Child's gender & & \\
$\quad$ Girl & $8(40)$ & \\
Boy & $12(60)$ & \\
Number of children & & \\
1 & $12(60)$ & \\
2 and more & $8(40)$ & \\
Regular inhaled corticosteroid treatment & $14(70)$ & \\
Yes & $6(30)$ & \\
No & & \\
\hline
\end{tabular}

received the same diagnosis. Some of the mothers' own statements are presented below:

"The disease began with pneumonia, my child had many bronchiolitis, we stayed in the hospital and he used too much antibiotics. Then, they referred us to this unit. I was very sad and scared at the beginning and wondered if we could get rid of this disease. However, the medications resulted in relief and it brought a certain level of order to our lives (M2)"

"My child started taking Ventolin ${ }^{\circledR}$ when aged 3-4 months old, but no definitive diagnosis could be made. They told us that they couldn't diagnose the condition. My child had difficulties in breathing and then had cough and nausea. He was on antibiotics and Ventolin ${ }^{\circledR}$ and got better for one month but then became sick. When the asthma diagnosis was made, the uncertainty disappeared. Together with the treatment, we stopped using antibiotics and relaxed a little bit (M3)"
"The diagnosis was made 2 years ago. Since my mother had asthma, I felt very sorry because I knew that it was a very hard process. Thus, I was afraid. I worried about no cure being found (M11)."

\section{Experience and Challenges}

Most of the parents stated that their domestic and business lives were affected because of effects on the marriage, being unable to take care of other children and being frequently admitted to emergency services. There were most common challenges with the use of inhalers and medications, struggle with longterm treatments, the recurrent nature of the disease, school problems, limitations in physical activity, not being able to care for other children and spousal problems. Some of the mothers' statements are presented below;

"We had a minimum of 3 unplanned physician visits, and 3-4 planned physician visits last year. In attack 


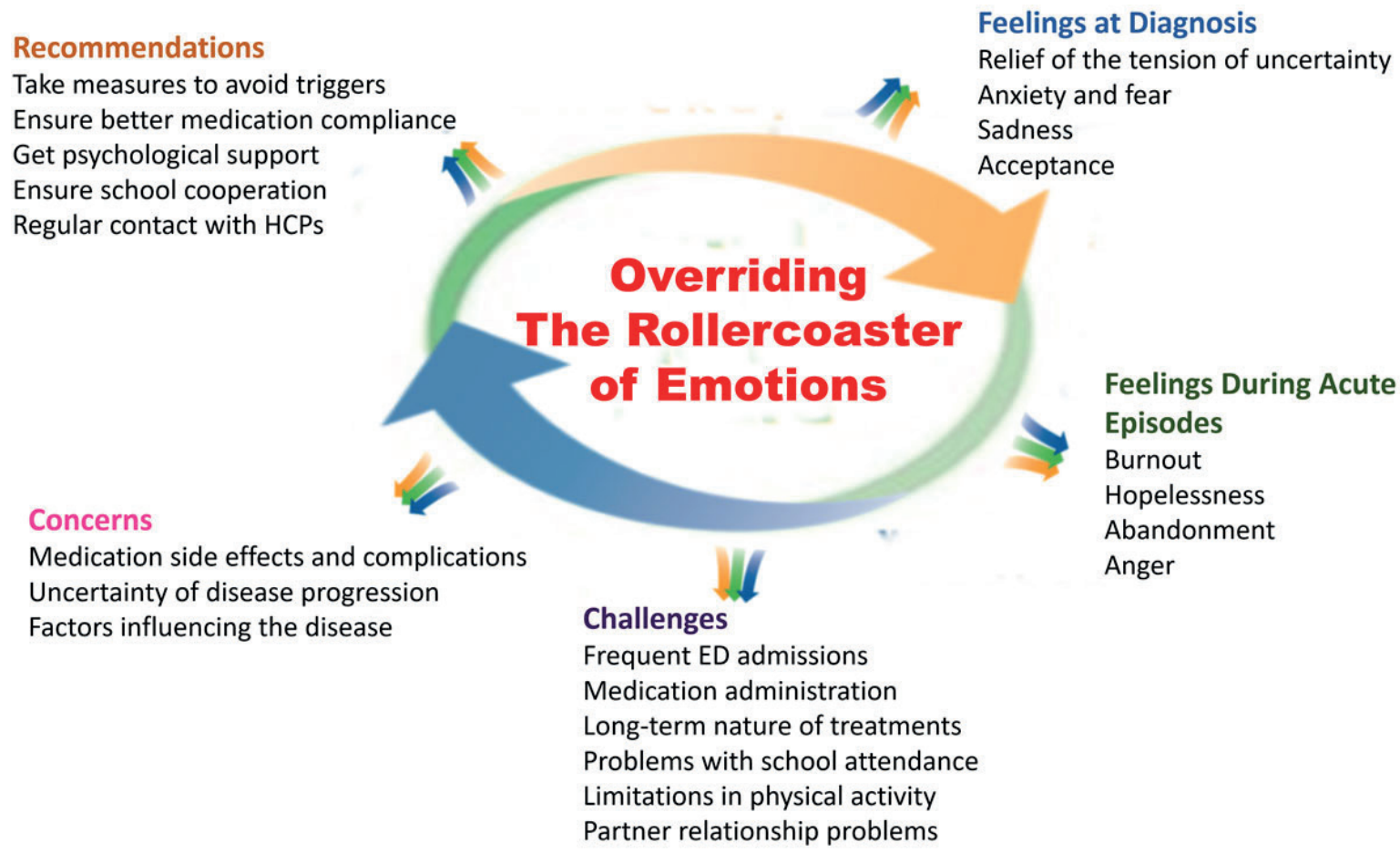

Fig. 1. Example of subthemes, theme and Main theme.

periods, we stop everything and take care of him. We cannot take care of our other child. We cannot pay attention to when he will come from school, what he will eat, or what he will do. His brother also feels sorry about this (M9)

"The antibiotics taste very bad, and children do not want to take them. She doesn't want to use the aerochamber. She walks for 5 minutes and easily feels tired. These are all very difficult (M2)"

"I feel so weak. My husband helps more often. We use the inhaler but unintentionally because I am very tired. The repetition of this process is very tiring for me. Besides these problems, we are upset because our child cannot participate in activities (M3)"

"Our child adheres to medications and has no problem taking doses, but we have significant problems at school. Sometimes there may be family activities at school, including working with children. She runs for a very short time and gets tired very quickly. She is upset because she can't keep up with her friends, which affects us. If it takes too long or she sweats too much, problems such as coughing or wheezing begin (M10)"
"We spend all the time in the emergency unit in winter. I often argue with my husband in the attack periods. (M17)"

"We have to pay attention since our child should never sweat a lot. If there is a sick child at school, we worry so much because our child can easily get sick. I always put Ventolin ${ }^{\circledR}$ and an aero-chamber in his bag and remind his teachers of his medication. I tell them to give him the inhaler (M15)"

\section{The feelings of mothers during the treatment}

The mothers experienced a feeling of anger and abandonment when they described not being able to take care of their child themselves and when she is not helped by her husband. The mothers felt burnout and hopelessness, when frequently admitted to emergency services, the workload and caregiving burden increased significantly. Most of the parents stated that their domestic and business lives were affected because of influences on the marriage or being unable to take care of other children. Some of the mothers' own statements are presented below. 
"I sometimes felt desperation and hopelessness. It had significant effects on my life. I feel abandoned. I'm very angry with my husband leaving all the responsibility to me (M1)."

"Our daily life is significantly affected. I always need to leave my job. Our lives are significantly affected. I'm burnt out. (M2)."

"My life is over. We almost cannot go out. I became obsessed with cleaning; I wipe everywhere using bleach and vinegar-water mixture. I have to shake the carpets every week, air the beds and sheets, change clothes every day, and clean everything using antiallergic soap. I feel so tired. (M7).

"It tires me a lot because I don't know which factors trigger the attacks. I think that she is OK but, after only 2 weeks, she falls sick. Then, I start to think about what I have done wrong. I start blaming myself and feel hopelessness (M18)."

\section{Concerns}

Mothers have concerns about the chronic nature of the disease, side effects of medications, complications that might develop, factors influencing the disease, and future plans. Some of the mothers' own statements are presented below.

"I am really worried about whether the disease is permanent. I am also particularly concerned about complications and respiratory arrest as I am a healthcare professional. (M1)."

"We always think 'what if the disease was over? Will we always be able to cope with it? and will these medications always be administered?'. After all, every medication has effects and side effects. What will the side effects of these medications be? I am pregnant now; will my second baby have asthma? How will our lives change? Of course, we have concerns and fears about the future (M2)."

"The weather conditions worry me a lot. If the weather is bad, I worry about how my daughter will be affected. Bad weather conditions and air pollution immediately affect her. It worries me a lot (M6)."
"We heard that Ventolin ${ }^{\circledR}$ may cause sudden cardiac arrest. This worries me. We learned that using inhaler would permanently enlarge the lungs and I am also very anxious about this. Besides these issues, the side effects also worry me a lot. Her cough has recovered now, but what will happen in the future? She takes so much medication for a child her age that I'm very anxious about it.. It makes me very anxious to think that this disease will become chronic (M13)."

\section{Coping and Recommendations}

Mothers made several recommendations that they believed would assist families in overcoming the emotional rollercoaster they described. The suggestions of mothers for minimizing the difficulties are measures against the triggers, compliance with medications and treatment, psychological support, and cooperation with teachers and keeping in touch with health professionals. Some of the mothers' own statements are presented below.

"I recommend paying more attention to the protective measures. A friend of my husband recommended cow milk; we used it for 2 weeks, as well as carob extract and other similar herbal products together with the medications, but none of them produced an effect. One should never use them without physician recommendation. Compliance with the medication and treatment is very important (M1)."

"They must comply with the treatment. It may sometimes be very difficult to accustom the children. It is also very difficult for parents to adapt to the process. However, when complying with the treatment regularly, I benefited from the therapy. The number of attacks decreased and we had more comfortable periods. Psychological support can be considered for a child in need. If not financially affordable, it is very difficult to outsource the psychological support. However, if the hospital offers such an option, they might be more comfortable (M2)."

"In case of an intense cough, they should stay away from pets and take measures against the triggers because staying in the same environment with a pet for only one hour may cause an increase in the 
attacks. Thus, it is very important to take measures against the triggers and allergies (M5)."

"A good treatment process and education play an important role. I wish we had more information about when and what to do. Mothers should never quit the therapy and keep in touch with medical staff. They should keep their eyes on their children. These children are very vulnerable. I love perfumes but I cannot use any perfume because of my child's hypersensitivity. I clean every day. The most important point I want to emphasize is that they should keep their eyes on their children and do their best to overcome this disease (M6)."

"I believe that teachers should also be informed. I think that the teachers do not know how to approach the children and which games they should play, which activities they should do. They do not know how to behave during the attack periods. The families should establish closer communication with and inform the teachers (M10)."

\section{Discussion}

The present study aimed to document the experience, perceptions and challenges of parents who have a child with asthma. The first theme was mother's feelings at disease diagnosis. Mothers emphasized certain specific points such as uncertainties until diagnosis, very frequent use of antibiotics, problems arising from frequently going to the emergency unit because of recurring symptoms, and relaxation because of the elimination of uncertainties after the diagnosis was made. In a systematic review examining the experiences of families having child with asthma, it was found that the parents experienced uncertainty and fear because of the lack of an exact diagnosis, and they had similar relaxation after the diagnosis. ${ }^{5,15,16}$ Taking care of a child with asthma is very difficult for the primary caregivers. Uncontrolled asthma causes a decrease in quality of life and is related with negative physical and psychological effects and four times higher costs. ${ }^{15,16}$

The second and third prominent theme concerned challenges and feelings during treatment. Experiences of problems contributed to hopelessness, feelings of abandonment, anger and burnout. The asthma-related difficulties of families were found to be frequent admissions to the hospital, increased workload and caregiving burden at home, problems with other family members, and effects on professional life. Similarly, in previous studies, it was reported that the workload of mothers increased, some mothers had to quit their jobs, they had to ignore their own needs, and the activities performed together with and the care for the spouse and healthy child(ren) were significantly reduced. ${ }^{17-19}$ It was emphasized that mothers clean the house almost every day and they change bedsheets every week. Additionally, they do not know what to do, feel desperate, constantly making an effort in order to prevent their children from getting sick, sleep beside their children at night and constantly keep their eyes on their children, and always take leave from their jobs during disease periods, which affects their professional life..$^{20,21}$ Challenges were feelings of guilt and blame, concerns about reproduction, feeling helpless and alone, feeling worried about the future, the burden and problems during the diagnostic process. The interpersonal challenges that were identified were the feeling of isolation, negative impacts on relationships, financial impacts, lack of knowledge and understanding among their community, lack of support, and lack of help from the health professionals. ${ }^{22}$

Mothers stressed the difficulties in administering medications. It was also determined that they tend to use complementary-alternative treatments in order to prevent the attacks. In a systematic review on the difficulties of families having child with asthma, it was reported that the families had difficulties in compliance with medications, which affects the control of asthma. The complexity of medications and the inability to understand asthma control causes asthma management driven by the beliefs of parents. ${ }^{23}$ Similarly, in previous studies, the causes of noncompliance with medications were as follows: the children not liking the 
taste and smell of medications, the emotional discomfort, the use of complementaryalternative treatments, the cease of use of medications in the asymptomatic period, and the intermittent use of medications. ${ }^{24,25}$ Some parents have difficulties in distinguishing the reliever medications from the prophylactic ones. Even the parents, who have child with a long history of asthma, may lack in knowledge or be confused. How to use the inhaler and the correct dosage and timing sometimes may not be understood accurately. They may employ different strategies in managing asthma depending on the perceived benefits of the use of medication. Some of the parents try to detect asthma before the intense symptoms, whereas others wait until the first asthmatic attack. The families stated that they tried different medications with an experimental approach, and they administered these medications based on their own decisions. ${ }^{23}$ The compliance with medications and treatment is vital for the control of asthma. For this reason, it is very important to raise parents' awareness as well as their compliance with therapy. ${ }^{25-27}$ Family's compliance with medication is vital for ensuring and maintaining routines at home. ${ }^{23}$

The fourth theme was concerns of mothers. The most important concerns of mothers about the caregiving process were about the permanence of the disease, side effects of the medications, and potential complications that might develop. Similarly, in previous studies, the families had concerns about the course of the disease and complications. Long-term use of medications also worried the families..$^{23,28,29}$ Moreover, families also stated worrying about the longterm effects of oral and inhaled steroids. Some of the participants stated that they worried about future steroid addiction of their children, as well as the caries and the effects on growth and development of organs. ${ }^{17,23}$ The families emphasized that asthma medications cause hyperactivity, concentration problems at school, sleep disorders, restlessness, and anxiety among the children. ${ }^{30-32}$ Families are the key actors playing a key role in children's compliance with medications. ${ }^{17,27,33}$ For this reason, they should be informed and trained by healthcare professionals. This training should be on time, consistent, updated, evidence-based, and specific to the individual. ${ }^{18}$ In several studies, it was emphasized that the families overlooked or underestimated the severity of their child(ren)'s disease, and this constituted a major obstacle for asthma management. ${ }^{32}$ This result suggests that there may be a deficiency in the knowledge level of families. In the present study, several families could accurately specify the causes and triggers of asthma (environmental factors, genetics, smoking, air pollution, allergy, infection, etc.). However, some of the mothers stated that they had no knowledge of asthma triggers. This result is in line with those obtained in previous studies. In a previous study, the families stated that they did not have sufficient knowledge, and this increased their concerns about the use of medication and disease management. ${ }^{23}$

The final theme was recommendations of mothers. In order to minimize problems, the mothers suggested taking measures against triggers, complying with medications and treatment, and cooperating with teachers, as well as receiving training and psychological support from their spouse and healthcare professionals. It was observed that the parents took measures against asthma attacks, especially for the triggers of attacks. The practices of families are as follows: frequently replacing bed sheets, ventilating the room, and doing cleaning on a regular basis. Similarly, in previous studies, the measures most frequently taken by families in order to cope with the disease were determined to be as follows: keeping the room moist and ventilated, not smoking at home, frequently changing bed sheets, using hypoallergenic beds, and limiting physical activity. ${ }^{20,21,25}$

In studies of the experiences of families, the families having child with asthma, emphasized the lack of training and psychological support provided by healthcare professionals. ${ }^{19,33-35}$ Moreover, in previous studies, it was reported that families had problems with school personnel concerning managing asthma and 
that many families did not send their children to school during periods of exacerbations. ${ }^{36}$ The mothers are generally the primary caregivers of children, and many mothers feel alone in managing asthma.

Family members are confident with the health service quality and their support positively affect the asthma management. ${ }^{23}$ In a systematic review on the obstacles and difficulties in asthma control, the most important factors were reported to be the families' knowledge level, beliefs, access to healthcare services, and trust in emergency services. ${ }^{24}$ Bellin et al. ${ }^{20}$ declared that the mothers felt that they were not understood by healthcare professionals in the hospital environment. Parents having a child with asthma generally need high-quality care and to be listened to, understood, and respected by healthcare personnel, as well as to be given training offering simple and understandable information. Health care professionals will be able to more effectively anticipate and address the needs of caregivers. ${ }^{23,37}$ Illness perceptions were associated with asthma control and emotional problems. ${ }^{38}$ Previously it was emphasized that establishing asthma action plans are necessary in order to minimize the problems of families. ${ }^{24,39-43}$

In conclusion, this is the first study that examines in detail the experience of mothers with children with asthma and the findings of the current study demonstrated the significant impact mothers emotional problems have on the parents' everyday life and the importance of health professionals' knowledge to identify and support mothers with these conditions. Acknowledging these experiences and their implications will improve interventions and support by health professionals as they assist families. For this purpose, it is recommended to establish asthma action plans in hospitals, offer written and verbal information to the families about diagnosis of disease, recognition, and treatment of symptoms, and use of medications by the healthcare professionals; prepare training guidelines, offer a supportive approach and regular follow-up, and meet psychosocial needs. Future research should examine the role of nurses and their experiences of supporting parents having children with asthma. Future research should concentrate on promoting awareness, education, advocacy, and support for such parents. It would be useful to compare this data with different societies and to examine the changes that will occur in our society over time.

\section{REFERENCES}

1. Misra SM. The current evidence of integrative approaches to pediatric asthma. Curr Probl Pediatr Adolesc Health Care 2016; 46: 190-194.

2. Cavkaytar O, Sekerel BE. Baseline management of asthma control. Allergol Immunopathol (Madr) 2014; 42: 162-168.

3. Civelek E, Cakir B, Boz AB, et al. Extent and burden of allergic diseases in elementary schoolchildren: a national multicenter study. J Investig Allergol Clin Immunol 2010; 20: 280-288.

4. Weinstein SM, Pugach O, Rosales G, Mosnaim GS, Walton SM, Martin MA. Family chaos and asthma control. Pediatrics 2019; 144: e20182758.

5. Lakhanpaul M, Culley L, Robertson R, et al. A qualitative study to identify parents' perceptions of and barriers to asthma management in children from South Asian and white British families. BMC Pulm Med2017; 17: 126.

6. Brown N, Gallagher R, Fowler C, Wales S.. Asthma management self-efficacy in parents of primary school-age children.J Child Health Care 2014; 18: 133-144.

7. Brooks JL, Asafu-Adjei J, Currin EG, Beeber LS. Exploring a broader context of the home environment and its relationship with asthma control in American Indian children. Res Nurs Health 2020; 43: 218-229.

8. Sekerel BE, Saraclar Y, Ones U, et al; Turkish National Allergy and Clinical Immunology Society. Childhood asthma perception in Turkey under reallife environment (CAPTURE) study. Pediatr Allergy Immunol 2001; 12: 266-273.

9. Dizdar EA, Civelek E, Sekerel BE. Community pharmacists' perception of asthma: a national survey in Turkey. Pharm World Sci 2007; 29: 199-204.

10. Soyer OU, Civelek E, Sekerel BE. Physicians' perception of childhood asthma in Turkey: more appropriate practice among female physicians. BMC Health Serv Res 2008; 23: 155. 
11. Smith JA. Qualitative psychology: a practical guide to research methods (3rd ed.). Thousand Oaks, California: Sage, 2015.

12. Başkale H. Nitel araştırmalarda geçerlik, güvenirlik ve örneklem büyüklügünün belirlenmesi. Dokuz Eylül Üniversitesi Hemşirelik Fakültesi Elektronik Dergisi 2016; 9: 23-28.

13. Murphy KR, Zeiger RS, Kosinski M, et al. Test for respiratory and asthma control in kids (TRACK): a caregiver- completed questionnaire for preschoolaged children. J Allergy Clin Immunol 2009;123: 833-839.e9.

14. Buyuktiryaki B, Sahiner UM, Yavuz ST, et al. Validation of the Turkish version of "Test for Respiratory and Asthma Control in Kids (TRACK)" questionnaire. J Asthma 2013; 50: 1096-1101.

15. O'Byrne PM, Pedersen S, Schatz M, et al. The poorly explored impact of uncontrolled asthma. Chest 2013; 143: 511-523.

16. Cousino MK, Hazen RA. Parenting stress among caregivers of children with chronic illness: a systematic review. J Pediatr Psychol 2013; 38: 809828.

17. Grover C, Armour C, Van Asperen PP, Moles RJ, Saini B. Medication use in Australian children with asthma: user's perspective. J Asthma 2013; 50: 231241.

18. Walker VG. Minority caregivers' emotional responses and perceptions of the emotional responses of their children to asthma: comparing boys and girls. Issues Ment Health Nurs 2013; 34: 325-334.

19. Chen SH, Huang JL, Yeh KW, Tsai YF. The stress of caring for children with asthma: a qualitative study of primary caregivers. J Nurs Res 2015; 23: 298-307.

20. Bellin MH, Land C, Newsome A, et al. Caregiver perception of asthma management of children in the context of poverty. J Asthma 2017; 54: 162-172.

21. Gibson-Scipio W, Krouse HJ. Goals, beliefs, and concerns of urban caregivers of middle and older adolescents with asthma. J Asthma 2013; 50:242-249.

22. Weber CL. Understanding fragile $X$ syndrome from a mother's perspective: challenges and resilience. Int J Qual Stud Health Well-being 2016; 1: 29512.

23. Fawcett R, Porritt K, Stern C, Carson-Chahhoud $\mathrm{K}$. Experiences of parents and carers in managing asthma in children: a qualitative systematic review. JBI Database System Rev Implement Rep 2019; 17: 793-984.

24. Lakhanpaul M, Bird D, Manikam L, et al. A systematic review of explanatory factors of barriers and facilitators to improving asthma management in South Asian children. BMC Public Health 2014; 14: 403.
25. Ahmad A, Sorensen K. Enabling and hindering factors influencing adherence to asthma treatment among adolescents: a systematic literature review. J Asthma 2016; 53: 862-878.

26. van Asperen PV. Deaths from childhood asthma, 2004-2013: what lessons can we learn? Med J Aust 2015; 202: 125-126.

27. Santer M, Ring N, Yardley L, Geraghty AW, Wyke $\mathrm{S}$. Treatment non-adherence in pediatric long-term medical conditions: systematic review and synthesis of qualitative studies of caregivers' views. BMC Pediatr 2014; 14: 63.

28. Coffey J, Cloutier M, Meadows-Oliver M, Terrazos C. Puerto Rican families' experiences of asthma and use of the emergency department for asthma care. J Pediatr Health Care 2012; 26: 356-363.

29. Klok T, Brand PL, Bomhof-Roordink H, Duiverman EJ, Kaptein AA. Parental illness perceptions and medication perceptions in childhood asthma, a focus group study. Acta Paediatr 2011; 100: 248-252.

30. Freidin B, Timmermans S. Complementary and alternative medicine for children's Asthma: satisfaction, care provider responsiveness, and networks of care. Qual Health Res 2008; 18: 43-55.

31. Sonney JT, Gerald LB, Insel KC. Parent and child asthma illness representations: a systematic review. J Asthma 2016; 53: 510-516.

32. Carroll WD, Wildhaber J, Brand PL. Parent misperception of control in childhood/adolescent asthma: the Room to Breathe survey. Eur Respir J 2012; 39: 90-96.

33. Archibald MM, Caine V, Ali S, Hartling L, Scott SD. What is left unsaid: an interpretive description of the information needs of parents of children with asthma. Res Nurs Health 2015; 38: 19-28.

34. Carrillo G, Perez-Patron MJ, Lucio RL, et al. The benefits and challenges of managing asthma in hispanic families in South Texas: a mixed- methods study. Front Public Health 2017; 5: 150.

35. Al Aloola NA, Nissen L, Alewairdhi HA, Al Faryan N, Saini B. Parents' asthma information needs and preferences for school-based asthma support. J Asthma 2017; 54: 946-956.

36. Shaw MR, Oneal G. Living on the edge of asthma: a grounded theory exploration. J Spec Pediatr Nurs 2014; 19: 296-307.

37. Foronda CL, Jawid MY, Alhusen J, Muheriwa SR, Ramunas MM, Hooshmand M. Healthcare providers' experience with gaps, barriers, and facilitators faced by family caregivers of children with respiratory diseases. J Pediatr Nurs 2020; 52: 49-53. 
38. Tiggelman D, van de Ven MO, van Schayck OC, Kleinjan M, Engels RC. The Common Sense Model in early adolescents with asthma: longitudinal relations between illness perceptions, asthma control and emotional problems mediated by coping. J Psychosom Res 2014; 77: 309-315.

39. Guarnaccia S, Quecchia C, Festa A, et al. Evaluation of a diagnostic therapeutic educational pathway for asthma management in children and adolescents. Front Pediatr 2020; 8: 39.

40. Anderson ME, Zajac L, Thanik E, Galvez M. Home visits for pediatric asthma-a strategy for comprehensive asthma management through prevention and reduction of environmental asthma triggers in the home.Curr Probl Pediatr Adolesc Health Care 2020: 50: 100753.
41. Swann JL, Griffin PM, Keskinocak P, et al. Return on investment of self-management education and home visits for children with asthma. J Asthma 2019; 1-10. doi: 10.1080/02770903.2019.1690660. [Online ahead of print].

42. Wang L, Timmer S, Rosenman K. Assessment of a University-Based Outpatient Asthma Education Program for Children.J Pediatr Health Care 2020; 34: 128-135.

43. Pedersen SE, Hurd SS, Lemanske RF, et al; Global Initiative for Asthma. Global strategy for the diagnosis and management of asthma in children 5 years and younger. Pediatr Pulmonol 2011; 46: 1-17. 